\title{
The Rare Reason of Fetal Cardiomegaly-Prenatal Diagnosis of Vein of Galen Aneurysmal Malformation
}

\author{
Leszczyńska Katarzyna*1 , Chojnicki Maciej ${ }^{2}$, Haponiuk Ireneusz ${ }^{2,3}$, Preis Krzysztof ${ }^{1}$ and Gierat Haponiuk \\ Katarzyna ${ }^{4}$ \\ ${ }^{1}$ Department of Perinatology, Medical University of Gdansk, Poland
}

${ }^{2}$ Department of Pediatric Cardiac Surgery, Copernicus Hospital in Gdansk, Poland

${ }^{3}$ Chair of Physiotherapy, Gdansk University of Physical Education and Sport, Poland

${ }^{4}$ Department of Rehabilitation, Medical University of Gdansk, Poland

Received: June 11, 2018; Published: June 20, 2018

*Corresponding author: Katarzyna Leszczyńska, Medical University of Gdansk. Department of Perinatology Ul. Kliniczna 1a, 80-210 Gdansk, Poland, Tel: +4858 34934 45; Email: leszczka@gmail.com

\author{
Abstract \\ Authors report the case of cardiomegaly associated with vein of Galen aneurysmal malformation. Prenatal diagnosis of this vein anomaly \\ enables plan the delivery and treatment in special neurosurgical department.
}

Keywords: Vein of Galen aneurysmal malformation; Cardiomegaly; Heart failure; Pregnancy

Abbrevations: VGM: Vein of Galen Malformations; VGAM: Vein of Galen Aneurysmal Malformations; VGAD: Vein of Galen Aneurysmal Dilation; CVPS: cardiovascular profile score; TTTS: Transfusion Syndrome

\section{Introduction}

Malformations of the Galen vein, also commonly referred to as Galen vein aneurysms, constitute a group of congenital malformations resulting from the abnormal development of a great cerebral vein, often called a Galen vein (vein of Galen malformations (VGM)). They are arteriovenous malformations of the choroidal system, draining blood into the great cerebral vein. Aneurysmal Galen vein malformations (vein of Galen aneurysmal malformations, VGAM) and aneurysmal Galen vein dilation (vein of Galen aneurysmal dilation, VGAD), are referred to as alleged malformations of the Galen vein. The first to describe the malformation of the great cerebral vein was J. Rudolph Jaeger in 1937 [1]. A previous description of the alleged malformation of Galen's vein was presented by Sigmund Steinheil in his monograph from 1895 about arteriovenous malformations [2], although in the light of current knowledge, the defect described by Steinhel would rather qualify for the alleged malformations of Galen's vein [3].

The pathogenesis of the defect was ultimately explained by Raybaud in 1989 [4]. Galen vein malformations are rare cerebral irregularities, do not exceed one percent of all intracranial vascular malformations [3], although they constitute about $30 \%$ of cerebral vascular malformations in children [1]. In the neonatal and infant group, Galen vein malformations may lead to heart failure, also seen during fetal life. Fetal heart failure is a condition where the cardiac output is insufficient in relation to the need. This results in impaired perfusion of fetal tissues and, in its extreme form, leads to generalized fetal edema. Currently, the degree of advancement of heart failure in the fetus is usually assessed on the Huhta scale (cardiovascular profile score - CVPS). Fetal heart failure may be caused by both reduced cardiac output to generate a cardiac output (heart failure with reduced cardiac output) and increased cardiac demand (heart failure with increased cardiac output). In this paper, we present a case of fetal cardiomegaly, diagnosed by prenatal echocardiography, which was caused by the presence of Galena arteriovenous malformation. The presented vascular pathology, diagnosed prenatally, is an example of early diagnosis of threatening heart failure in the fetus, as well as in the newborn immediately after birth. The basic symptom of cardiomegaly with increased cardiac output diagnosed in prenatal studies was caused by significant hemodynamic flow through a large intracerebral arterio-venous malformation. 


\section{Case report}

The 31-year-old patient in the 37th week of the first pregnancy was directed to echocardiography of the fetus due to cardiomegaly, found in an ultrasound examination at 36 week of pregnancy. In ultrasound performed at 12 and 21-week normal fetal development was observed. In the fetal echocardiogram, a symmetrical enlargement of all the heart cavities $(\mathrm{H} / \mathrm{C}=0.65)$ was confirmed, with normal anatomy of the heart and large vessels. Hyperkinetic circulation was detected - slightly accelerated flows through the heart valves and increased ventricular contractility (left ventricular ejection fraction LVEF $=80 \%$ ). Doppler examination revealed abnormal reverse flow in the aortic isthmus and descending aorta during diastole (Figure 1). According to the commonly accepted CVPS scale, the condition of the cardiovascular system was estimated at 8/10 (minus 2-for HA / CA). The reason for these changes was the large arterio-venous malformation of Galen vein, revealed during the same study. Prenatal diagnosis of vascular abnormalities allowed for planning treatment.

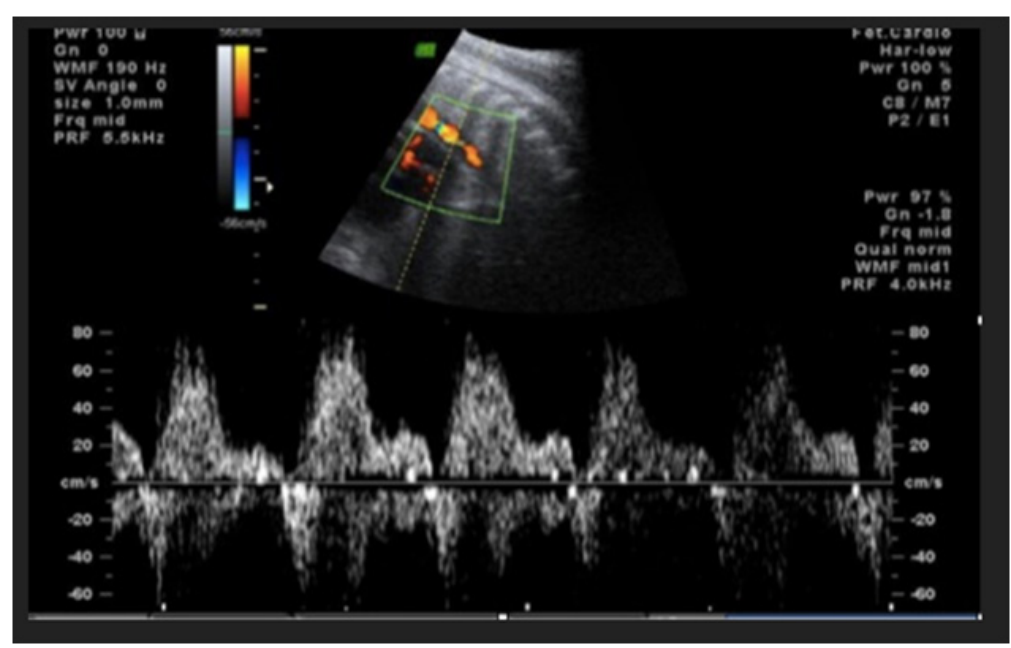

Figure 1: Abnormal reverse flow in the descending aorta.

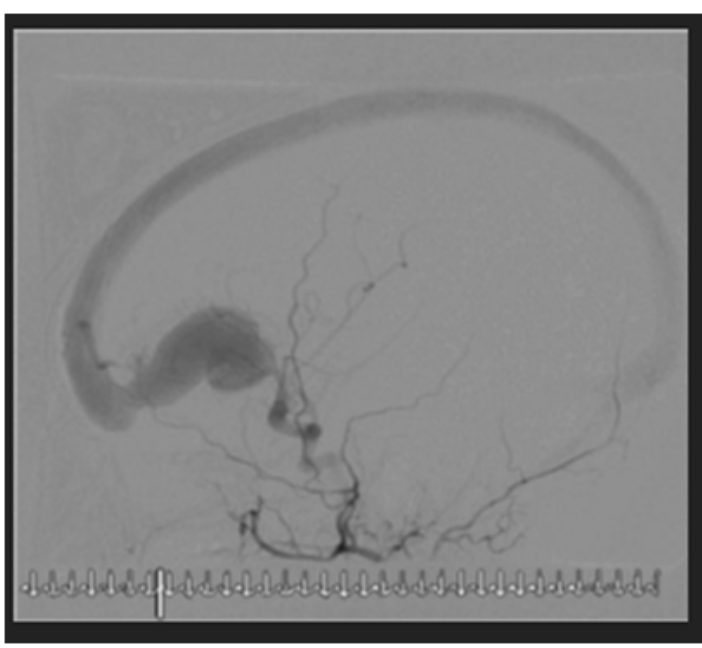

Figure 2: Malformation of Galen's Vein in angiography.

The patient was referred to the Perinatology and Perinatal Cardiology Clinic of the Medical University in Warsaw, where the diagnosis and planned neurosurgical treatment of the newborn was confirmed. Pregnancy was completed in the 38th week of pregnancy by caesarean section. A newborn male with a weight of $3420 \mathrm{~g}$ has been rated 9 points on the Apgar scale. Next, the boy was transported to the Department of Neurosurgery, Polish Institute of Mother and Child Care, where, after further diagnosis and confirmation of the diagnosis, surgical treatment was planned (Figure 2). Before the surgery there was no need for catecholamine treatment, the child only received Spironol orally at a dose of $1 \times 6.25 \mathrm{mg}$. The treatment took place two months after delivery; a procedure was performed to completely exclude from the circulation and remove the arteriovenous hemangioma of the left frontal lobe, by access via left-sided fronto-temporal craniotomy. The postoperative period went without complications. Further annual observation of the child's development did not confirm significant deviations from the normal state. Psychological examination of the annual child showed only about 1-month delay in speech development.

\section{Discussion}

Heart failure is a consequence of damage to the heart function as a pump, which leads to the development of symptoms of circulatory failure in the fetus as well. For practical reasons, it is worth distinguishing heart failure with a low output, and heart failure with an increased output (Table 1). The first group will include fetuses with heart failure due to a heart defect (eg Ebstein's syndrome, a common atrio-ventricular canal, stenosis of the aortic valve), cardiac arrhythmias (supraventricular tachycardia), and premature closure of the ductus arteriosus or foramen ovale, myocarditis or cardiomyopathy. The second group will consist of fetuses with tumors with high vascularity (eg neuroblastoma, teratoma), cardiac arrythmias (third degree atrioventricular block), arteriovenous fistulas (e.g. Galen's arteriovenous malformation, lung sequestration), and transfusion syndrome (TTTS). Regardless of the cause, the cardiovascular profile score(CVPS) is extremely useful in assessing the degree of heart failure. It allows objectifying 
the stage of heart failure, evaluating the prognosis in a patient, and monitoring the effects of its treatment.

Table 1: Causes of heart insufficienty divided into with low output and increased output.

\begin{tabular}{|c|c|}
\hline $\begin{array}{c}\text { Causes of heart insufficienty } \\
\text { with low output }\end{array}$ & $\begin{array}{c}\text { Causes of heart insufficienty } \\
\text { with increased output }\end{array}$ \\
\hline $\begin{array}{c}\text { Heart defects- Ebstein anomaly, } \\
\text { common atrio-ventricular canal, } \\
\text { aortic valve stenosis. }\end{array}$ & $\begin{array}{c}\text { Tumors with high vascularity (eg } \\
\text { neuroblastoma, teratoma). }\end{array}$ \\
\hline $\begin{array}{c}\text { Cardiac arrhythmias- } \\
\text { supraventricular tachycardia. }\end{array}$ & $\begin{array}{c}\text { Arteriovenous fistulas (e.g. Galen's } \\
\text { arteriovenous malformation, lung } \\
\text { sequestration). }\end{array}$ \\
\hline $\begin{array}{c}\text { Premature closure of the ductus } \\
\text { arteriosus or foramen ovale. }\end{array}$ & TTTS \\
\hline Myocarditis and cardiomyopathy. & $\begin{array}{c}\text { Cardiac arrythmias (third degree } \\
\text { atrioventricular block). }\end{array}$ \\
\hline
\end{tabular}

The anomaly presented at work was only revealed in advanced pregnancy, despite the correct results of previous ultrasound examinations. The doctor performing the ultrasound examination worried about fetal cardiomegaly, after the extension of imaging diagnostics in the hospital, Galen malformation was detected. Precise malformation imaging required the use of a colored Doppler. Theoretical knowledge of the possible causes of cardiomegaly allowed for a quick diagnosis of the underlying problem [5-7]. It should be emphasized that the hemodynamic condition of the fetus was good, and only 2 points for the significant fetal cardiomegaly were subtracted from the CVPS scale. Regeneration of the atrioventricular valves or exudates in body cavities was not recorded. There was no pulsation in the umbilical vein, and the flow through ductus venosus remained normal. Therefore, probably due to ultrasound examination, the stage of rapid malformation enlargement and the state threatening cardiac insufficiency was captured.

Depending on the week of pregnancy, in which Galen malformation was detected, and the severity of symptoms of heart failure, an individual decision about continuation or termination of pregnancy is made. In the presented case, cardiomegaly and arteriovenous malformation were diagnosed in 37 week of pregnancy that is, practically, in the term of labour. After six days, the pregnancy was resolved by Caesarean section. A more difficult decision is rapidly increasing circulatory failure in 28-29 or the first thirty weeks of pregnancy. Completion of pregnancy is most often associated with the impossibility of surgical treatment and predictable complications of prematurity, while its continuation may lead to generalized edema of the fetus and intrauterine death. Each time the decision is made individually, using the latest medical knowledge, and taking into account the conscious opinion of pregnant women. Based on literature data - according to the experience, most premature births due to Galen anomalies and full circulatory failure ended in deaths of newborns. Survival was recorded in only one case prepared pharmacologically for delivery with digoxin [8]. The location and size of the hemangioma determine the method of treatment.

The most common treatment is surgery, which, however, does not always have to be connected with the necessity of open treatment by the craniotomy method. Embolization is more and more often used, that is, the introduction of the sclerosing material through the blood vessels, which closes the aneurysm's light to exclude the vascular defect from the cerebral circulation. Such treatment is carried out during a diagnostic examination cerebral angiography [9-11]. Radiotherapy is a less frequently used method of treatment. There are also hemangiomas that do not cause symptoms - they do not qualify for treatment using any of the currently available methods of invasive therapy. Patients with hemangiomas of this type remain under neurosurgical control and are treated only symptomatically.

\section{References}

1 Jaeger JR, Forbes RP, Dandy WE (1937) Bilateral congenital cerebral arteriovenous communications aneurysm. Trans Am Neurol Ass 63: 1736.

2 Steinheil SO (1895) Ueber einen Fall von Varix aneurysmaticus im Bereich der Gehirngefaesse. Würzburg: F Fromme p. 1-56.

3 P Lasjaunias, Terbrugge K, Piske R, Lopez Ibor L, Manelfe C (1987) Vein of Galen dilatation: Anatomo-clinical forms and endovascular treatment. Fourteen cases explored and/or treated between 1983 and 1986 Neurochirugie 33(4): 315-333.

4 Raybaud CA, Strother CM, Hald JK (1989) Aneurysms of the vein of Galen: Embryonic and anatomical features relating to the pathogenesis of the malformation. Neuroradiology 31: 109.

5 Paternoster DM, Manganelli F, Moroder W, Nicolini U (2003) Prenatal diagnosis of vein of Galen aneurysmal malformations. Fetal Diagn Ther 18: 408-411.

6 Doyle NM, Mastrobattista JM, Thapar MK, Lantin Hermoso MR (2005) Perinatal pseudocoarctation: echocardiographic findings in vein of Galen malformation. J Utrasound. Med 24(1): 93-98.

7 Chevret L, Durand P, Alvarez H, Lambert V, Caeymax L, et al. (2002) Severe cardiac failure in newborns with VGAM. Prognosis significance of hemodynamic parameters in neonates presenting with severe heart failure owing to vein of Galen arteriovenous malformations. Intensive Care Medicine 28(8): 1126-1130.

8 Janiak K, Respondek-Liberska M (1998) 18 months observation of a child with a prenatal diagnosis of Galena arterio-venous malformation. The case of August 1998, Poland.

9 Lasjuanias P, Hui F, Zerah M, Garcia Monaco R, Malherbe V, et al. (1995) Cerebral arteriovenous malformations in children. Management of 179 consecutive cases and review of the literature. Child's Nervous System 11(2): 66-79.

10 Lasjuanias P, Rodesch G, Pruvost P, Francoise G, Laroche FG, et al. (1989) Treatment of vein of Galen aneurysmal malformation. Journal of Neurosurgery 70(5): 746-750.

11 Zerah M, Garcia Monaco R, Rodesch G, Terbrugge K, Tardieu, et al (1985) Hydrodynamics in vein of Galen malformations. Child's Nervous System 8(3): 111-117. 
(c) (P) This work is licensed under Creative Submission Link: https://biomedres.us/submit-manuscript.php

$\begin{array}{ll}\text { BIOMEDICAL } & \text { Assets of Publishing with us } \\ \text { RESEARCHES } & \text { - Global archiving of articles } \\ \text { - Immediate, unrestricted online access } & \text { - Rigorous Peer Review Process } \\ & \text { - Authors Retain Copyrights } \\ \end{array}$

